\title{
DE QUE MODO A GRAMÁTICA PODE CONTRIBUIR PARA A FUNCIONALIDADE DO ENSINO DE LÍNGUA : MATERNA?
}

\section{HOW GRAMMAR CAN CONTRIBUTE TO THE FUNCTIONALITY OF MOTHER LANGUAGE TEACHING?}

Maria Auxiliadora Ferreira Lima - UFPI ${ }^{1}$

\section{RESUMO}

Este artigo tem por objetivo refletir sobre o ensino de gramática nas aulas de língua materna dentro de uma abordagem que focaliza a funcionalidade deste ensino. Se partirmos do princípio de que os três pilares básicos do ensino de língua materna atuam sobre um elemento comum, o texto, que tem como alvo a construção e a reconstrução de significação, a sala de aula requer um espaço para uma reflexão sobre a gramática enquanto elemento imprescindível na organização dos enunciados, do texto. Tendo em vista essa perspectiva, situamos inicialmente alguns pressupostos teóricos básicos da Teoria das Operações Enunciativas de Antoine Culioli $(1990,2002)$ para o desenvolvimento da reflexão tais como a concepção de linguagem enquanto atividade, o conceito de noção, estabilidade e deformabilidade, para em seguida, mostrarmos, a partir do agenciamento de marcas gramaticais, como se dá a construção de sentido da piada em alguns textos que se configuram nesse gênero. Analisaremos, assim, 12 piadas, buscando mostrar como determinadas marcas léxico-gramaticais contribuíram para a construção das mesmas, gerando a deformabilidade. Concomitante ao processo de construção da piada, exploraremos sua desconstrução, demonstrando como este tipo de atividade contribui para que o aluno perceba que a gramática articulada ao léxico está a serviço do texto, ou seja, da construção/desconstrução de seu sentido.

PALAVRAS-CHAVE: Gramática; piada; significação; ensino.

1 Doutora em Linguística e Língua Portuguesa pela Universidade Estadual Paulista Júlio de Mesquita Filho. Email: dora.fl@uol.com.br 


\begin{abstract}
The aim of this article is to reflect on the teaching of grammar in mother language classes through an approach that focuses on the functionality of this teaching. If we assume that the three basic pillars of mother language teaching are based on a common element, the text, which has as a target the construction and reconstruction of meaning. The classroom requires a space for the reflection on grammar as an indispensable element of the utterances organization listed in the text. According to this perspective, we initially present some basic theoretical assumptions of the Theory of Enunciative Operations of Antoine Culioli $(1990,2002)$ for the development of reflection such as the design of language as activity, the concept of notion, deformability and stability. Then we show, starting from the grammatical mark agency, the construction of meaning of the joke in some texts which are in this genre. We analyze 12 jokes, trying to show how certain lexico-grammatical marks contributed to the construction of the jokes, generating deformability. Concomitant to the process of construction of the joke, we will explore its deconstruction, seeking to show how this type of activity contributes to point out to the student that grammar articulated to lexicon is being used by the text, namely, the construction/ deconstruction of its meaning.
\end{abstract}

KEYWORDS: Teaching; Grammar; Joke; Meaning.

\title{
INTRODUÇÃO
}

Neste artigo, defendemos o ensino de gramática em uma perspectiva enunciativa sob a vertente de uma prática reflexiva que tem sua origem no texto. Esta prática está centrada na gramática vista como suporte para a construção e reconstrução de significação do texto e não em estudos de conteúdos gramaticais compartimentados, desvinculados do texto, mais especificamente, dos seus enunciados e, consequentemente, de uma situação de enunciação. A reflexão proposta tem fundamentalmente uma preocupação de natureza pedagógica, razão pela qual ousamos delinear, por meio de algumas atividades, alguns caminhos que configuram o ensino de gramática subsidiadopor uma abordagem enunciativa 
A sala de aula, como bem defende Neves (2010, p.173), "é, em primeiro lugar, um espaço de reflexão, e as atividades têm de caminhar : sempre sobre essa base”. No que diz respeito às aulas de língua materna, a reflexão deve ser uma constante no tripé que dá sustentáculo a esse ensino - leitura, escrita e gramática. As atividades de leitura e escrita na sala de aula requerem uma reflexão e, por que não refletir também sobre a gramática enquanto elemento responsável pela organização dos enunciados, dos textos que lemos e que produzimos?

E como podemos construir esta reflexão em sala de aula? Sabemos que um ensino de língua materna pautado predominantemente em conteúdos e regras gramaticais não tem contribuído para o domínio da língua na pluralidade dos discursos. Os conteúdos gramaticais ainda ocupam uma boa parte dos programas de ensino de Língua Portuguesa ${ }^{2} e$ suas abordagens desvinculam a gramática da língua em uso, do texto, dos enunciados. Os livros didáticos também ainda refletem essa realidade. Por mais que os livros didáticos tenham evoluído qualitativamente, não é difícil encontrarmos, em livros publicados no triênio 2013-2015, abordagens gramaticais direcionadas, de forma camuflada, ou não, para definições, classificações e identificações. Esse tipo de abordagem leva, muitas vezes, o aluno a questionar a utilidade do estudo de determinados conteúdos gramaticais por não encontrarem uma funcionalidade no aprendizado dos mesmos. Na realidade, o cerne do problema não está no ensino de gramática, mas em sua abordagem. Sabemos que uma abordagem predominante centrada em conceitos, classificações, identificações não permite que o aluno adquira um conhecimento reflexivo da gramática de sua língua em situações efetivas de usos, materializada nos textos, nos enunciados.

Muito se tem discutido o ensino de gramática e um ponto comum dessas discussões é que a necessidade de um redirecionamento permanece, os avanços, ou seja, o ensino de gramática em articulação com a língua em uso, ainda não constitui uma prática consolidada. $\mathrm{O}$ professor precisa ser o condutor do processo, respaldado emposturas teóricas.Como observa

2 Recentemente tive a oportunidade de constatar tal fato ao ler alguns planos de ensino de Língua Portuguesa do Ensino Fundamental de uma escola pública, referentes ao ano de 2014 
Antunes (2014, p. 23),“(...) não existe apenas um ponto de vista teórico : válido. Podemos buscar em teorias diferentes aqueles suportes que podem apoiar os objetivos, as prioridades que elegemos para nossa atividade, neste caso, as atividades de exploração e análise da linguagem”.

Cabe, então, ao professor analisar esta ou aquela teoria, avaliando se determinados pressupostos teóricos podem auxiliá-lo na sua prática pedagógica, dando-lhe subsídios para as atividades de linguagem desenvolvidas em sala de aula.

Para a nossa proposta, discutiremos o ensino de gramática em uma abordagem que leve o aluno a se familiarizar com o processo de construção e desconstrução de sentido a partir do agenciamento de marcas. Desta forma, pensamos em um ensino de gramática pautado em uma prática reflexiva, mas não associada a uma reflexão restrita a questões gramaticais que atendam a um conteúdo programático,mas a questões gramaticais que alicerçam o texto, ou mais precisamente, os enunciados que o constituem em seu processo de construção de significações. Esta prática reflexiva insere-se em uma abordagem enunciativa da gramática subsidiada pela Teoria das Operações Enunciativas de Antoine Culioli. Neste tipo de abordagem não há espaço para se trabalhar o ensinode gramática pautado em um conjunto de conteúdo a ser repassado para os alunos; um ensino de gramática desvinculado dos usos linguísticos, ou seja, da língua em uso; um ensino de gramática desvinculado da significação dos enunciados, dos textos.

Para o desenvolvimento deste artigo, incialmente, situaremos a reflexão proposta em uma perspectiva enunciativa, em seguida apresentaremos alguns princípios básicos da teoria das Operações Enunciativas, buscando articulá-los, na medida do possível, com o ensino de gramática. Posteriormente, analisaremos alguns textos, no gênero piada, mostrando como o agenciamento de marcas lexicais e gramaticais contribuiu para a sua construção, para em seguida, apresentarmos as considerações finais. 


\section{Situando a reflexão em uma perspectiva enunciativa}

Esta reflexão não está centrada em aspectos linguísticos \gramaticais dentro de uma visão estática de língua, buscamos uma reflexão no âmbito da articulação linguagem e língua que objetiva levar o aluno a entender o processo de construção e desconstrução de significação do enunciado, o jogo das interrelações linguísticas que se manifestam no enunciado, no texto, através de marcas. Vale lembrar que não enunciamos por meio de unidades linguísticas soltas (unidades lexicais e gramaticais), gramática e léxico estão em constante integração. Construímos significações por meio de enunciados e, para isto, fazemos uso do léxico e da gramática. Não há enunciados, textos sem a ancoragem articulada dessa dupla. O léxico não é simplesmente adicionado ao enunciado, precisamos de elementos gramaticais, de categorias linguísticas para que as relações léxico-gramaticais se estabeleçam nos enunciados a partir das relações de predicação.

Trazer o ensino de gramática para a vivência da linguagem em sala de aula permite que o aluno perceba a inutilidade das memorizações de conceitos gramaticais, das classificações e das identificações de valores preestabelecidos. Prática esta que em nada contribui para a competência discursiva do aluno, por não trazer resultados funcionais. Daí o aluno tantas vezes se perguntar - para que eu preciso saber o que é um sujeito, o que é um objeto? E assim vai apresentando uma série de questões que ficam, na maioria das vezes, sem resposta. Saber classificar, por exemplo, um sujeito como indeterminado não é o bastante, o relevante é que ele saiba em que aquele sujeito semanticamente indeterminado está contribuindo para a construção referencial de um enunciado em sua situação de interação verbal. A indeterminação semântica constitui uma escolha do sujeito enunciador pautada em uma intencionalidade. Quando o aluno diz à professora -professora, quebraram a janela, ele pode desconhecer o agente da ação e está querendo apenas informar o fato de a janela estar quebrada, no entanto é possível também que ele não queira entregar o colega responsável pela ação e daí usar o verbo na $3^{\circ}$ pessoa do plural sem a marca do pronome.

Por que em vez de o professor deter-se, por exemplo, na classificação de uma oração ou de um dado termo, ele não direciona o aluno para 
uma reflexão sobre as relações que as orações estabelecem? Essa postura : metodológica contribui para que o aluno não tome o conectivo como o elemento responsável pela classificação sintática da oração. O que evita, por exemplo, que o aluno em um enunciado como Não sei quando Maria voltará de viagem, classifique a oração quando Maria voltará de viagem como oração subordinada adverbial temporal em função do quando, ou seja, por ter tomado a marca quando como um conectivo introdutor de uma oração subordinada adverbial. Se o aluno entender as relações de predicação que se estabelecem, ele vai entender também que o termo quando, nesse enunciado, não constitui marca de uma oração adverbial temporal. Por isso, o importante é que ele perceba que:

- a oração não sei é localizada em relação a quando Maria voltará de viagem;

- a oração quando Maria voltará de viagem constitui o fato não sabido pelo sujeito enunciador;

- do ponto de vista sintático, a oração quando Maria voltará de viagem constitui argumento de Não sei;

- a marca quando estabelece uma relação temporal não situada, não determinada com voltará de viagem - Maria voltará de viagem em um dado tempo que eu não sei precisar.

Em nossa reflexão, pautada na Teoria das Operações Enunciativas (doravante TOE), consideramos que os valores referenciais de um enunciado são construídos, o que significa que as marcas agenciadas para a construção do enunciado vão assumir um valor somente no enunciado. Então por que não explorar a diversidade desses valores a partir de um texto? Por exemplo, se em um dado texto trabalhado em sala de aula ocorre a marca bem em um enunciado do tipo Pedro é bem estudioso, o professor explora o valor damarca bem, levando o aluno a pensar, através da manipulação de dados, a diferença entre os enunciados Pedro é bem estudioso e Pedro é estudioso. É importante que o aluno perceba que a alteração de sentido ocorrida no enunciado com a retirada da marca bem, indica que a ausência da marca bem revela que o sujeito enunciador ao não colocá-la no enunciado assim como qualquer outra que assuma 
o mesmo valor de bem, não quer ressaltar o quanto Pedro é estudioso mas apenas ressaltar que ele é estudioso. Ainda nessa reflexão, o professor : pode levar o aluno a perceber que a relação que se estabelece entre bem e estudioso é diferente da relação que se estabelece entre canta e bem, por exemplo, em um enunciado como Pedro fala bem. O elemento bem vai contribuir para o valor referencial de cada um desses enunciados de forma distinta. Nesse processo, o aluno está construindo e desconstruindo valores. No primeiro enunciado, bem marca que o enunciador não quer apenas dizer que Pedro é estudioso, ele quer ressaltar que Pedro é muito estudioso, a palavra bem marca uma elevação no grau da qualidade de Pedro, ser estudioso, ele não é só estudioso, ele é bem estudioso. Já no segundo (Pedro fala bem), o sujeito enunciador não quer dizer que Pedro fala mas que Pedro tem uma maneira desenvolta de se expressar, a marca bem evoca isso. O professor deve pensar junto com os alunos situações de enunciações distintas para enunciados como Pedro fala e Pedro fala bem, considerando que uma marca não expressa um único valor e que o valor que uma marca assume no enunciado tem relação com o valor referencial que o sujeito enunciador intenciona construir.

\section{A Teoria das Operações Enunciativas e o ensino de gramática: algumas articulações}

Trabalhamos com a concepção de enunciado na perspectiva da TOE, concebido comoo produto de uma atividade significante de produção e reconhecimento de formas linguísticas por parte dos sujeitos enunciadores ${ }^{3}$. $\mathrm{Na}$ TOE o sujeito enunciador é uma instância enunciativa e não deve ser confundido com o sujeito do enunciado, o sujeito sintático. Essa atividade significante de produção e reconhecimento de formas linguísticas faz parte da atividade de linguagem. Para Culioli (1990) a atividade de linguagem é uma atividade de representação, de referenciação e de regulação. É uma atividade de representação por permitir a construção de representações. A atividade de representação envolve três níveis: representação mental (nível 1), representação linguística (nível 2) e representação metalinguística (nível

3 Não há enunciação sem sujeitos enunciadores. $\mathrm{O}$ sujeito enunciador tem uma origem subjetiva que se constrói necessariamentecomo intersubjetiva em razão do sujeito enunciador suscitar um coenunciador que é um sujeito enunciador em potencial. 
3). O nível de representação mental é do domínio da cognição. Trata-se de representações que organizam experiências que nós desenvolvemos ao longo de nossa vida, são representações construídas a partir de nossas relações no mundo. Não temos acesso direto a esse nível, ele se dá por intermédio do nível 2, o nível das representações linguísticas em que se tem o agenciamento de formas que viabilizam o acesso indireto ao nível das representações mentais. Não há uma correspondência direta entre as representações mentais e os representantes do nível 2. Se assim fosse, como diz Culioli, teríamos uma relação termo a termo, ou seja, uma marca e um único valor. Esse aspecto reforça a inadequação de um ensino de gramática pautado em classificações, em valores preestabelecidos, pois não temos, como ele bem observa, uma marca correspondendo a um único valor mas uma marca correspondendo a vários valores ou vários valores a uma marca. É assim que a língua funciona em nossa atividade de linguagem. Um ou outro valor só se estabelece no e pelo enunciado.

Como atividade de referenciação, a linguagem nos permite remeter a uma dada realidade. Nessa atividade, temos operações por meio das quais a linguagem torna possível o dizer alguma coisa do mundo, sobre o mundo (LEBAUD,2012). Através de um agenciamento de formas se exprime alguma coisa a propósito do que se fala. São essas formas agenciadas que constituem a materialidadeda língua. Temos a construção de valores referenciais que são produzidos pelos enunciados e cuja existência se dá apenas por meio deles. O valor referencial de um enunciado é construído por este enunciado e corresponde ao que ele diz de seu referente. Ele não tem outra existência a não ser a que o enunciado lhe confere.

É também uma atividade de regulação em razão da relação intersujeitos requerera justamentos pois, muitas vezes, na atividade de linguagem, quando o sujeito enunciador constrói uma dada significação, a significação reconstruída pelo sujeito coenunciadornão corresponde de forma satisfatória a significação construída pelo sujeito enunciador, fazendo-se necessários os ajustamentos. A enunciação coloca em jogo a relação intersujeitos que Lebaud chama de posições enunciativas que são estabelecidas e marcadas, de maneira estruturada, por formas agenciadas da língua. Como explica Valentim: 
A atividade de regulação prende-se, com a construção de ajustamentos entre os sujeitos da enunciação, em ambos os planos - de representação e de referenciação. Uma vez que na origem da significação estão asrepresentações cognitivas de cada indivíduo, a significação reconstruída poderá não coincidir inteiramente com a significação construída. Consequentemente, ter-se-ão que dar ajustamentos, manifestando-se assim a vertente reguladora da atividade de linguagem (VALENTIM, 1998, p.35).

Estabilidade e plasticidade são propriedades da linguagem. Não é suficiente apenas falar, construir enunciados para se estabelecer uma sintonia com o outro, é necessário também que sejam feitos os ajustes nessa atividade de construção e reconstrução de significação (CULIOLI, 2002, p.164).Isto nos leva à questão da regularidade e dadeformabilidade na linguagem. Para Culioli, os sistemas linguísticos formam sistemas dinâmicos que são regulares mas com uma margem de variação devido a fatores diversos. $\mathrm{Na}$ atividade de linguagem, lidamos com fenômenos que apresentam estabilidade mas também plasticidade e labilidade. Aqui, entra a questão da deformabilidade, tendo-se em vista que "a deformação é uma transformação que modifica uma configuração, de sorte que certas propriedades permanecem invariantes sob transformação, enquanto que outras vão variar.” (CULIOLI, 1990, p.129). Na TOE, os conceitos estabilidade e deformabilidade caminham juntos.

Que elo podemos estabelecer entre essa concepção de linguagem como atividade de representação, de referenciação e de regulação e o ensino de gramática? Essa concepção mostra a articulação entre linguagem e língua. A gramática permeia essa vinculação, considerando que a língua só se materializa através do texto, dos enunciados, não por meio de um amontoado de marcas mas através de um agenciamentode marcas, resultantes de operações de linguagem. Uma reflexão centrada na construção de significação conduz o aluno a perceber, por um lado, como os elementos gramaticais, categorias linguísticas e a entonação (quando se trata de enunciados na modalidade oral) contribuem para a construção de significação de um enunciado e, por outro, como valores referenciais podem ser construídos e desconstruídos. Ele estará, assim, lidando com 
a funcionalidade do ensino de gramática e vivenciando a linguagem. $\mathrm{O}$

: funcional desse ensino, por exemplo, não é o aluno saber identificar o valor específico ou não específico de um pronome indefinidomas ter o domínio da construção e desconstrução desse valor, saber passar de um valor específico para um não específico, de um não específico para um específico. E se ele adquire esse domínio, saberá, a partir do agenciamento de marcas do enunciado, quais marcas contribuem para essas alterações.

Um outro aspecto a ressaltar é que os enunciados são constituídos dentro de um ambiente textual e de um ambiente situacional. A gramática precisa ser explorada dentro dessa integração, pois o enunciado é inseparável de suas condições de produção, ou seja, de sua situação de enunciação.

\section{Explorando a construção léxico-gramatical em piadas}

Conforme já ressaltamos, a prática reflexiva na exploração da gramática em sala de aula não deve ocorrer em detrimento dos outros pilares básicos do ensino de língua materna - leitura e produção de textos na ampla diversidade dos gêneros. A gramática é apenas um componente fundamental que não pode ser ignorado pois está intrinsecamente vinculado à constituição do texto, inserido em um dado gênero. Tal vinculação reforça a importância de se trabalhar a gramática com o intuito de familiarizar o aluno com o processo de construção de significação do texto explorado em sala de aula, contribuindo assim para o desenvolvimento de sua competência discursiva.

Considerando que o desencadeador da abordagem gramatical em sala de aula seja o texto e que a exploração da gramática deve ocorrer, sobretudo, em função do desvendar das construções de significação, tomamos as piadas como objeto de análise linguística para a compreensão do sentido do texto. Nossa escolha está em consonância com a posição de Possentireferente às razões para se trabalhar a piada, dentre as quais citamos:

Pelo menos para um estudioso da linguagem em geral e dos discursos em particular. Em primeiro lugar, do ponto de vista estritamente linguístico, as piadas interessam como peças textuais que exibem com bastante clareza um domínio 
da língua de alguma forma complexo (e as piadas mostram que todos o são). Qualquer domínio que uma teoria linguística tematize pode ser exemplificado por uma piada cujo funcionamento depende basicamente de sua análise e interpretação (em geral, um desses textos permite pelo menos uma dupla interpretação). Em outras palavras, o que quero dizer é que, para ilustrar hipóteses ou princípios de análise linguística, ao invés de utilizar dados forjados ad hoc, ou que são excessivamente chatos ou mesmo pouco verossímeis, servindo apenas como exemplos escolares, os especialistas poderiam escolher uma piada corrente. Com isso, poderiam ter um exemplo autêntico, envolver os interlocutores em verdadeiros problemas de interpretação, e, mesmo, proceder às abstrações necessárias para exibir um mecanismo linguístico de um certo tipo. (POSSENTI, p.27, 1998)

Além de Possenti, citamos também a posição de Neves em relação à utilização de piadas nas aulas de língua materna:

Pode até parecer estranho dizer isso, mas as piadas são textos particularmente provocadores de reflexão, instigantes, e por isso mesmo, de boa escolha para o trabalho com língua e linguagem nas escolas. Considero muito evidente a suposição de que, para qualquer pessoa sensível interessada na linguagem, depois do riso que a piada provoca ainda fica a alegria de ver e admirar de que modo o jogo de obtenção de sentido e de efeito de humor foi explorado. (NEVES, 2010, p.173)

Em sintonia com as razões de Possenti e Neves para se trabalhar a piada em sala deaula, passemos à análise de 12 piadas ${ }^{4}$,objetivando mostrar como se dá a construção de cada uma delas, a partir do agenciamento de marcas lexicais e gramaticais. Buscamos explorarnas análises, como o professor pode trabalhar tais marcas com o intuito de explorar oprocesso

4 As piadas foram extraídas da internet através de uma busca no google por piadas para serem trabalhadas em sala de aula. 
: de construção e dedesconstrução da piada. Em relação ao processo de sua : construção, partimos do princípio de que o sujeito enunciador faz uso da deformabilidade para provocar a piada, ele modifica a configuração esperada para que haja uma ruptura da estabilidade e ocorra a piada. É o que mostraremos nas análises. Vejamos:

\section{Piada 1}

- Doutor, já quebrei o braço em vários lugares.

- Se eu fosse o senhor, não voltaria mais pra esses lugares

Nesse texto, a unidade lexical lugares é o elemento chave para a construção da piada, ele vai ser o elemento desencadeador da deformabilidade. O Sujeito Enunciador ${ }_{2}$ (doravante $\mathrm{SE}_{2}$ ) ao reconstruir a significação do que é dito pelo Sujeito Enunciador ${ }_{1}$ (doravante $\mathrm{SE}_{1}$ ), não entende lugares como partes de um membro físico (braço). Ele toma lugar no sentido de espaço físico, ambiente, não levando em consideração o cotexto ${ }^{5}$ quebrei o braço. Ao tomar lugares como espaço físico, ele provoca a deformabilidade.

A segunda ocorrência de lugares provoca a ruptura por não assumir o mesmo valor da primeira ocorrência, ou seja,o $\mathrm{SE}_{2}$ não remete lugares para partes do braço quebrado. Vejamos:

Sentido da $1^{\circ}$ ocorrência de lugar: partes de uma unidade (braço)

Cotexto da $1^{\circ}$ ocorrência: quebrou o braço

Sentido da $2^{\circ}$ ocorrência de braço: espaço físico, ambiente

Cotexto: voltaria

O professor pode explorar por que a segunda ocorrência delugares assume um sentido diferente em relação a primeira ocorrência. Na segunda ocorrência o SE utiliza o verbo voltar que evoca um sentido diferente para lugares, por predicar a X a propriedade de retornar a um ponto de origem. Enquanto que na primeira ocorrência, lugares estabelece uma relação com braço em termos de pontos de localização.

Desconstruindo a piada: $O$ professor pode solicitar aos alunos que pensem em uma outra possibilidade de fala do $\mathrm{SE}_{2}$ que eliminaria a piada. Por exemplo, construir um enunciado em que a ocorrêncialugar não

$5 \mathrm{O}$ cotexto diz respeito ao ambiente textual em que a unidade lexical se encontra inserida. 
assumisse o sentido de espaço físico. Manipulando o texto, poderíamos ter:

- Doutor, já quebrei o braço em vários lugares.

- Se eu fosse o senhor tomaria cuidado, pois esses lugares são muito sensíveis. (???)

Se a fala do $\mathrm{SE}_{2}$ tivesse sido essa, não haveria piada, a estabilidade permaneceria poislugares continuaria remetendo a partes do braço. Esse tipo de reflexão leva o aluno a perceber que a variação de sentido das ocorrências da unidade lexical lugares se deu em razão do cotexto e que o sentido dessa ocorrência foi construído no e pelo enunciado. ${ }^{6}$

\section{Piada 2}

- Estou com vontade de ganhar na loteria de novo.

- O quê? Você já ganhou?

- Não. Mas já tive essa vontade antes.

Nesse texto, a expressão de novo, colocada em posição final no enunciado, é o elemento desencadeador da piada, pois essa posição leva o $\mathrm{SE}_{2}$ a pensar que o $\mathrm{SE}_{1}$ já ganhou, pelo menos uma vez, na loteria. Trata-se de uma posição que gera uma ambiguidade ${ }^{7}$ por levar a duas interpretações: a expressão de novo pode estar relacionada somente a ganhar na loteria ou a estou comvontade. $\mathrm{O} \mathrm{SE}_{1}$ faz uso dessa colocação para gerar possibilidades diferentes de sentido. $\mathrm{O} \mathrm{SE}_{2}$ assume a primeira interpretação e pergunta de maneira admirada, estabelecendo uma relação de ajustamento para se certificar do fato - O quê? Você já ganhou? -Daí decorre a ruptura na resposta do $\mathrm{SE}_{1}$, que não valida a predicação ganhar na loteria, em vez de confirmar, ele diz - Não. Mas já tive essa vontade antes -, pois é a segunda interpretação que está sendo considerada pelo $\mathrm{SE}_{2}$.

Desconstruindo a piada: aqui, o professor pode explorar a desconstrução da piada através da manipulação da posição do termo de novo, levando o aluno a verificar em qual posição no enunciado essa expressão eliminaria a piada por não deixar margem para uma segunda

6 Para a Teoria das Operações Enunciativas, o sentido não é dado, ele é construído no e pelo enunciado.

7 Cançado (2012) chama de ambiguidade sintática. 
interpretação. No decorrer da reflexão, os alunos concluirão que não : ocorrerá piada, se a expressão de novo vier apósa ocorrência com vontade: Vejamos:

- Estou com vontade, de novo, de ganhar na loteria

- O quê? Você já ganhou?

- Não. Mas já tive essa vontade antes. (????)

\section{Piada 3}

Tem Pé de Porco?

A dona de casa pede para o menino:

- Filho, vá ver se o açougueiro tem pé de porco.

O garoto sai e volta meia hora depois:

- Não consegui ver, mãe. Ele estava de sapato!

Nesse texto, a ocorrência lexical pé de porco é o elemento desencadeador da piada pois o $\mathrm{SE}_{2}$ (filho), a partir da pedido do $\mathrm{SE}_{1}$ (a mãe), estabelece uma possível relação de identidade entre o pé do açougueiro e o pé de porco, instaurando a deformabilidade quando diz - ele estava de sapato.

Desconstruindo a piada: o professor pode levar o aluno a pensar em construções que eliminem essa identidade. Perguntar, por exemplo, o que o açougueiro vende no açougue. Uma das respostas seria pé de porco - O açougueiro vende pé de porco. Vender seria a palavra chave para eliminar a deformabilidade e, consequentemente, a piada:

Tem Pé de Porco?

A dona de casa pede para o menino:

- Filho, vá ver se o açougueiro tem pé de porco para vender

O garoto sai e volta meia hora depois:

- Não consegui ver, mãe. Ele estava de sapato! (???)

\section{Piada 4}

Duas “cobras” olhando o céu, numa noite estrelada:

- Como nós somos insignificantes.

- Você e quem? 
O $\mathrm{SE}_{1}$ (cobra 1$)$ atribui a marca nós um valor genérico,nós remete aos elementos da espécie cobra. $\mathrm{O} \mathrm{SE}_{2}$ não toma nós como genérico para não se incluir no grupo dos elementos insignificantes. Para tanto atribui a nós o valor referencial de $E u+$ uma terceira pessoa e se desvencilha da propriedade de ser insignificante, introduzindo um terceiro elemento, ainda não definido na situação contextual, através da marca quem em um enunciado interrogativo - Você e quem?

Desconstruindo a piada: $O$ professor pede aos alunos que se coloquem na posição do $\mathrm{SE}_{2}$ admitindo a possibilidade de também o $\mathrm{SE}_{1}$ tê-loinserido entre as cobras insignificantes. Diante dessa possibilidade, pedir aos alunos para reconstruir o diálogo:

- Como nós somos insignificantes.

- Nós quem? (???)

A marca nós articulada à marca quem deixa em aberto a possibilidade do $\mathrm{SE}_{2}$ também inserir-se entre as cobras insignificantes. $\mathrm{O}$ professor pode trabalhar as possíveis respostas do $\mathrm{SE}_{1}$, explorando valores referenciais do nós nessa situação de enunciação.

\section{Piada 5}

Professor: - Quantos corações nós temos?

Aluno: - Dois, professor.

Professor: - Dois!?

Aluno: - Sim, o meu e o seu!

O $\mathrm{SE}_{1}$ (o professor) utiliza o nós em um valor genérico, remetendo a espécie, cada elemento da espécie possui um coração, o pronomenós não está atribuindo um valor específico a nenhum ser humano. Já o $\mathrm{SE}_{2}$ (aluno) não toma nós como genérico, ele lhe atribui o valor de eu + você e responde ao $\mathrm{SE}_{1}$ considerando a totalidade dos corações existentes em uma relação distributiva: $\mathrm{x}_{1}$ (o professor) tem um coração e $\mathrm{x}_{2}$ (o aluno) tem um coração. Há uma atividade de regularidade, pois o $\mathrm{SE}_{1}$ surpreende-se com a resposta de $\mathrm{SE}_{2}$ e diz - dois!? A entonação marca a falta de sintonia entre a resposta do $\mathrm{SE}_{2}$ e a resposta que o $\mathrm{SE}_{1}$ esperava ouvir. $\mathrm{O} \mathrm{SE}_{1}$ ao dizer dois!'realiza uma atividade de regulação. $\mathrm{E}_{\mathrm{o}} \mathrm{SE}_{2}$ ( aluno) explica ressaltando a totalidade dos corações existentes - Sim. O meu e o seu. A 
deformabilidade se dá exatamente nessa resposta de natureza somatória.

$\vdots$ assumam a posição do $\mathrm{SE}_{2}$ e respondam a pergunta:

Professor: - Quantos corações nós temos?

Aluno: - um professor/ cada um de nós tem um coração (???)

A estabilidade dessas respostas rompem com a piada pois não deixam margem para a deformabilidade. $O$ professor pode explorar ainda a marca desencadeadora da desconstrução da piada, ou seja, a ocorrência um articulada a coração.

\section{Piada 6}

Não deixe sua cadela entrar na minha casa de novo. Ela está cheia de pulgas.

- Diana, não entre nessa casa de novo. Ela está cheia de pulgas.

Nesse texto, o elemento lexical chave é cadela, ele vai ser um desencadeador da piada porque o $\mathrm{SE}_{2}$ ignora a relação anafórica, entre sua cadela e ela:

Não deixe sua cadela entrar na minha casa de novo. Ela está cheia de pulgas.

$\mathrm{O} \mathrm{SE}_{2}$ provoca a deformabilidade, quando atribui um valor referencial ao pronome ela distinto do valor atribuído pelo $\mathrm{SE}_{1}$ :

Diana, não entre nessa casa de novo. Ela está cheia de pulgas.

O pronome ela deu margem para a troca propositada de referente pois a identidade de referente desmonta a piada.

Desconstruindo a piada: o professor pode levar os alunos a pensarem que elemento lexical, se repetido, não daria margem para o $\mathrm{SE}_{2}$ trocar de referente:

Não deixe sua cadela entrar na minha casa de novo. Sua cadela está cheia de pulgas.

A segunda ocorrência de sua cadela elimina a ruptura referencial e desmonta a piada pois não deixa espaço para uma interpretação dúbia de referente. 
O professor pode também pedir aos alunos que se coloquem na posição do $\mathrm{SE}_{2}$ e dirijam-se a cadela de forma a eliminar a piada. $\mathrm{Na}$ : reconstrução do texto, teríamos:

- Não deixe sua cadela entrar na minha casa de novo. Ela está cheia de pulgas

- Diana, não entre nessa casa de novo. Você está cheia de pulgas. (???)

\section{Piada 7}

Numa festa, o secretário do presidente fila um cigarro. O presidente comenta:

- Não sabia que você fumava.

- Eu fumo, mas não trago.

- Pois devia trazer

$\mathrm{O} \mathrm{SE}{ }_{1}^{8}$ ignora a relação semântica entre fumar e tragar, quando o $\mathrm{SE}_{2}$ diz - eu fumo mas não trago. O SE utiliza trago como ocorrência do verbo trazer e não como ocorrência do verbo tragar. O cotexto fila um cigarro, fumo constrói o sentido de trago como parte do processo de fumar.

Desconstruindo a piada: $\mathrm{O} \mathrm{SE}$ provoca a deformabilidade quando usa trago no sentido de carregar, ter consigo um cigarro. $O$ professor pode solicitar que os alunos reconstruam o texto, usando a ocorrência trago em um sentido que elimine a piada:

\section{Piada 8}

Numa festa, o secretário do presidente fila um cigarro. O presidente comenta:

- Não sabia que você fumava.

- Eu fumo, mas não trago.

- Não é bom tragar (???)

Texto 8 (Piada 8)

A professora está ensinando o uso de pronomes e pede ao Carlinhos:

- Faça uma frase com o pronome consigo

8 Nesse texto, temos duas situações de Enunciação: uma em que o SE narra o fato (Sit0), anterior a outra situação de Enunciação (Sit1) em que se dá a interação entre o $\mathrm{SE}_{1}$ e o $\mathrm{SE}_{2}$. 
- Eu não consigo correr muito.

Nesse texto, a deformabilidade ocorre porque o $\mathrm{SE}_{2}$ altera a classe gramatical da ocorrência consigo, provocando a piada. O SE solicita o uso do termo consigo na função de pronome e o $\mathrm{SE}_{2}$ utiliza-o como verbo.

Desconstruindo a piada: o professor pode sair desse tipo de abordagem metalinguística e levar os alunos a pensarem em uma situação em que a marca consigo assume o valor de um pronome. Por exemplo, levar os alunos a pensarem que Carlinhos gosta de falar com ele mesmo, que Carlinhos trouxe o livro com ele, e pedir aos alunos que construam um enunciado em que a marca consigo mostre isso. A partir dos enunciados construídos, estimula os alunos a verificarem em que essa marca se distancia da primeira (eu não consigo correr muito). Assim, pensando em uma situação que se adequa à construção de enunciados como Carlinhos fala consigo mesmo. Carlinhos trouxe o livro consigo -,ele explora as relações cotextuais desses elementos, destacando os termos com os quais a ocorrência consigo estabelece uma relação. É importante também que o aluno perceba o processo de desconstrução da piada, se o enunciado do $\mathrm{SE}_{2}$ fosse:

A professora está ensinando o uso de pronomes e pede ao Carlinhos:

- Faça uma frase com o pronome consigo

- Carlinhos fala consigo mesmo.

\section{Piada 9}

Professor:- Joaquim, diga o presente do indicativo do verbo caminhar Aluno: - Eu caminho... tu caminhas... ele caminha...

Professor: - mais depressa!

Aluno: Nós corremos, vós correis, eles correm!

Nesse texto, o professor pode começar explorando o sentido dos três pontinhos para mostrar porque o professor diz mais depressa seguido de um ponto de exclamação, levando o aluno a perceber que mais depressa é o elemento desencadeador da piada, pois é a partir daí que o $\mathrm{SE}_{2}$ (aluno) estabelece uma gradação semântica caminhar - correr. A deformabilidade que provoca a ruptura se manifesta porque o $\mathrm{SE}_{2}$ entende a ocorrência 
mais depressa em relação a caminhar rápido e não em relação a falar mais rápido a conjugação do verbo caminhar no presente do indicativo.

Desconstruindo a piada: uma forma interessante seria o professor encenar a situação com os alunos, ou seja, pedir que eles conjuguem o verbo caminhar no presente do indicativo, de forma bem compassada para que, no decorrer da conjugação, ele solicite uma maior rapidez. Após a encenação, o professor pede que eles reconstruam o texto dentro desse cenário, fazendo uso do recurso da entonação:

Professor: - Joaquim, diga o presente do indicativo do verbo caminhar Aluno: - Eu caminho... tu caminhas... ele caminha...

Professor: - mais depressa!

Aluno: Nós CORREMOS, VÓS CORREIS, ELES CORREM! (????)

Piada 10

Mariazinha analise a frase, há uma mulher olhando pela janela, é singular ou plural?

- Singular.

- Muito bem! Agora você Joãozinho, há várias mulheres olhando pela janela, o que é?

- Fofoca!!!

$\mathrm{Na}$ piada 10, podemos observar que a estabilidade permanece até a resposta do $\mathrm{SE}_{2}$ (Mariazinha). $\mathrm{O} \mathrm{SE}_{1}$ faz uma pergunta de natureza gramatical de caráter metalinguístico que é respondida de forma adequada. A resposta do $\mathrm{SE}_{3}$ (Joãozinho) sai da questão gramatical (singular-plural) e instala-se no nível pragmático, calcada no cultural, rompendo com a estabilidade. No cultural, costuma-se dizer que as mulheres gostam de fofoca. Se pensarmos em termos de uma representação mental, a noção ${ }^{9}$ que o $\mathrm{SE}_{3}$ tem de fofoca vincula-se a um grupo de mulheres juntas, olhando alguma coisa, conversando.

Desconstruindo a piada: Se a resposta do $\mathrm{SE}_{3}$ permanecesse no nível gramatical, a estabilidade não seria rompida:

Mariazinha analise a frase, há uma mulher olhando pela janela, é

9 O termonoção tem um lugar importante na Teoria das Operações Enunciativas. É anterior ao léxico e faz parte de uma representação mental. Culioli a define como um feixe de propriedades físico-culturais que nós apreendemos através de nossa atividade enunciativa de produção e de compreensão de enunciados. (CULIOLI, 1999, p.9) 
singular ou plural?

- Singular.

- Muito bem! Agora você Joãozinho, há várias mulheres olhando pela janela, o que é?

- Plural (????)

\section{Piada 11}

PROFESSORA: Bruno, que nome se dá a uma pessoa que continua a falar, mesmo quando os outros não estão interessados?

BRUNO: Professora

Esse texto segue a mesma linha do texto 10, há um salto não esperado para o pragmático. A resposta do $\mathrm{SE}_{2}$ continua no metalinguístico, no nível lexical, mas provoca a ruptura com a estabilidade por alterar a noção de professora. A deformabilidade ocorre por conceber professora como uma pessoa tagarela, ou seja, como uma pessoa que fala muito mesmo quando os outros não estão interessados.

Desconstruindo a piada: $\mathrm{O}$ professor pode explorar o sentido de professora e tagarela em um enunciado como $A$ professora é tagarela, levando os alunos a pensarem por que não haveria piada se a resposta do $\mathrm{SE}_{2}$ fosse, por exemplo, tagarela, inconveniente:

PROFESSORA: Bruno, que nome se dá a uma pessoa que continua a falar, mesmo quando os outros não estão interessados?

BRUNO: Tagarela, inconveniente (???)

\section{Piada 12}

A professora diz:

- Ontem fui criança. Isso é passado.

- Hoje sou bonita. O que é isso, Joãozinho?

- É mentira, professora!

Nesse diálogo a professora está explorando a noção de tempo. Para construir a piada, o $\mathrm{SE}_{2}$ sai do metalinguístico, no nível gramatical, ignorando a questão do tempo gramatical através das marcas ontem e hoje, articuladas com as marcas verbais fui e sou em uma relação contrastiva de tempo semântico (passado e presente)e realiza uma manifestação acerca 
da asserção eu sou bonita por meio de uma modalidade apreciativa. Ao desmentir a asserção do $\mathrm{SE}_{1}$ (professora), o $\mathrm{SE}_{2}$ (Joãozinho) ignora a : natureza metalinguística da pergunta e faz uma apreciação sobre o que é dito. Estabelece, então, a deformabilidade por romper com a estabilidade ao não dar continuidade a indicação de tempo semântico solicitado pelo $\mathrm{SE}_{1}$ e fazer uso de um valor modal. Detém-se no teor da asserção afirmativaHoje sou bonita e manifesta uma apreciação. $\mathrm{O} \mathrm{SE}_{2}$ estabelece a deformabilidade por considerar que a professora ao enunciar hoje sou bonita estava se considerando bonita.

Desconstruindo a piada: o professor pode solicitar que os alunos reconstruam o texto, dando a resposta gramatical solicitada pela professora:

A professora diz:

- Ontem fui criança. Isso é passado.

- Hoje sou bonita. O que é isso, Joãozinho?

- Presente. (???)

\section{CONSIDERAÇÕES FINAIS}

Neste artigo defendemos o ensino de gramática nas aulas de língua materna em uma abordagem voltada para a construção e reconstrução de significação dos enunciados, do texto. A gramática deve ser trabalhada em sintonia com as atividades de leitura e escrita, tendo-se em vista que é a partir do agenciamento de marcas que o SE constrói e reconstrói significações. $\mathrm{O}$ aluno ao ler um texto parte de marcas para reconstruir significações e, ao produzi-lo, agencia marcas para produzir significações. No âmbito da articulação léxico e gramática, cabe ao professor levar o aluno a refletir sobre o papel que determinadas marcas lexicais e gramaticais, resultantes de escolhas do SE, contribuem para a construção da significação dos enunciados, do texto.

Essa conduta propicia que o trabalho do professor com a gramática se desvincule de uma relação de conteúdos gramaticais listados em um plano de curso a ser abordado em uma dada série.

O professor, tendo consciência de que não há enunciado sem gramática e que no texto, gramática e léxico estão articulados, pode nas atividades de leitura e escrita, de forma sistemática, explorar o papel de determinadas marcas gramaticais para a construção do sentido 
do enunciado naquele texto. Naturalmente, é preciso que esse tipo de : reflexão leve em conta o grau de maturidade dos alunos e, para isso, o professor pode tomar como parâmetro a série em que se encontram os alunos Sua intuição, experiência servirão de instrumentos para a dosagem dessa reflexão. Levando em conta esse aspecto, o professor fará a escolha das marcas a serem trabalhadas de forma natural naquele texto, ou seja, como elemento a serviço da construção de sentido do texto, levando os alunos a refletirem sobre o sentido que uma determinada marca assume no enunciado, manipulando esse enunciado para que o aluno perceba a relação que tal marca estabelece com outros termos. Desta forma o aluno vai percebendo desde cedo que um termo sempre está em relação a outro termo, a percepção dessas relações ajudará o aluno na compreensão do texto, objeto de sua leitura e de sua escrita.

Ilustramos esta forma de abordar o ensino de gramática através da análise de alguns textos que se enquadram no gênero piada. Consideramos que se trata de um gênero interessante para se trabalhar a gramática a serviço do texto em razão da deformabilidade que rege a construção da piada, afetando a estabilidade. Um SE agencia marcas para construir um dado sentido e o outro SE a partir desse agenciamento, agencia outras marcas para que o sentido construído ou esperado pelo SE seja desastibilizado, resultando na constituição da piada.Neste tipo de atividade, o professor instiga não só o aluno a buscar, no texto, as marcas desencadeadoras da piada, mas também, a perceber as relações de sentido que tais marcas estabelecem no texto para que se dê a piada no plano linguístico ou pragmático.

Nos 12 textos analisados, as marcas desencadeadoras da piada mostraram a falta de sintonia entre o dizer do $\mathrm{SE}_{1}$ eo dizer do $\mathrm{SE}_{2}$, resultantes dos seguintes aspectos:

- Atribuíram sentidos distintos para uma mesma unidade lexical(piada 1).

- Atribuição de valor referencial distinto (piada 2)

- Atribuição de uma relação de identidade para referentes distintos (piada 3)

- Atribuição de valores referenciais distintos para uma mesma marca pronominal nós (piadas 4 e 5 ) 


\section{- Retomada referencial distinta (piada 6)}

- Alteração de classe gramatical (piada 8)

- Passagem de um nível gramatical para um nível semântico (piada 9)

- Passagem de um nível semântico para um nível pragmático (piadas 10 e 11)

- Passagem de um nível gramatical para um nível apreciativo através da mudança de categoria linguística (tempo e modalidade - piada 12)

Dentro de uma relação de intersubjetividade, a deformabilidade é acionada por um dos sujeitos enunciadores, através de um dado agenciamento de marcas, para que a piada se estabeleça. Nos textos analisados, $\mathrm{o} \mathrm{SE}_{2}$ foi predominantemente o responsável pela construção da piada. Tivemos apenas um caso (a piada 1) em que o $\mathrm{SE}_{1}$ assumiu a condução do processo. Nessa relação de intersubjetividade, um dos sujeitos enunciadores desconsidera o valor de uma determinada marca no âmbito lexical ou gramatical, construído pelo outro sujeito enunciador, para reconstruir um outro valor quer seja no plano sintático, semântico ou pragmático. Todos eles rompendo com a estabilidade.

\section{REFERÊNCIAS BIBLIOGRÁFICAS}

ANTUNES, Irandé. Gramática contextualizada:"limpando o pó das ideias simples”. São Paulo:Parábola, 2014.

CANÇADO, Márcia. Manual de semântica. São Paulo: Contexto, 2012.

CULIOLI, Antoine. Pourune linguistiquede l'énonciation. Tome 1. Paris:Ophrys, 1990.

Pour une linguistique de l'énonciation. Tome3. Paria:Ophrys, 1999

Variationssurlalinguistique. Paris:Klincksieck, 2002. 
DE VOGUÉ, Sarah.Culioli após Benveniste:Enunciação, linguagem, : integração. In ROMERO, Márcia e BIASOTTO-HOMMO, Milenne (Orgs)Linguagem e enunciação: representação, referenciação e regulação. São Paulo: Contexto, 2011.

FRANCKEL, Jean-Jaques. Referência, referenciação e valores referenciais. In ROMERO, Márcia e BIASOTTO-HOMMO, Milenne (Orgs) Linguagem e enunciação: representação, referenciação e regulação. São Paulo: Contexto, 2011.

NEVES, Maria Helena de Moura. Ensino de língua e vivência de linguagem: temas em confronto. São Paulo:Contexto, 2010.

LEBAUD, Daniel. Sémantiquegrammaticale: autor d'emplois<marginaux>dufutursimple. ActesduColloqueMiroir,. Paris, 2012, pp 143-157.

LIMA, Maria Auxiliadora Ferreira. O Ensino de gramática em uma perspectiva enunciativa. In LIMA, Ma. A. F; COSTA, C. de S. M. da; ALVES F. F. (Orgs.) Reflexões linguísticas eliteráriasaplicadas ao ensino. Teresina: EDUFPI, 2010.

NEVES, Ma. Helena de Moura. Ensino de língua e vivência de linguagem:temas em confronto. São Paulo:Contexto, 2010.

POSSENTI, Sírio. Os humores da língua: análises linguísticas de piadas. Campinas, SP: Mercado de Letras, 1998.

VALENTIM, Helena Topa. Predicação de existência e operações enunciativas. Lisboa:Edições Colibri, 1998. 